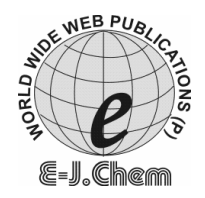

\title{
A New Inhibition Kinetic Spectrophotometric Method for the Determination of Resorcinol
}

\author{
MOHSEN KEYVANFARD \\ Faculty of Science, Islamic Azad University-Majlesi Branch, Isfahan, Iran. \\ keyvan45638@yahoo.com \\ Received 23 August 2009; Revised 18 October 2009; Accepted 15 December 2009

\begin{abstract}
A new, simple, inexpensive and fast kinetic spectrophotometric method was developed for the determination of trace amounts of resorcinol over the range of $0.02-0.80 \mu \mathrm{g} / \mathrm{mL}$. The method is based on the inhibitory effect of resorcinol on the formaldehyde catalyzed oxidation reaction of of cresyl violet by bromate in acidic media is reported. The reaction was monitored spectrophotometrically by measuring the decrease in absorbance of cresyl violet at $596 \mathrm{~nm}$ with a fixed-time $0.5-2.5 \mathrm{~min}$ from initiation of the reaction. The detection limit is $0.017 \mu \mathrm{g} / \mathrm{mL}$ and relative standard deviation of 0.1 and $0.5 \mu \mathrm{g} / \mathrm{mL}$ resorcinol for six replicate measurements was 2.6 and $2.9 \%$, respectively. The
\end{abstract} \\ method was applied to the determination of resorcinol in water samples.
}

Keywords: Inhibition kinetic, Resorcinol, Spectrophotometric method, Cresyl violet.

\section{Introduction}

Resorcinol is an important industrial chemical material used widely in the fields of rubber, plastics and organic synthesis industries, wood adhesives, fire retardants and UV stabilizer, etc. It is derived from various resins and tannins but most commonly by fusing sodium hydroxide with meta-benzene-disulfuric acid. Global output of resorcinol in 2004 was about 41.83 million tons. This compound is a moderate toxic substance and easily soluble in water ${ }^{1}$. There is a growing need for developing highly sensitive, simple methods to detect resorcinol in the wastewater at a low level. The major methods for the determination of resorcinol that have already been reported are high performance liquid chromatography ${ }^{2-6}$ and gas chromatography ${ }^{7,8}$. The separations of these methods are efficient, but require expensive instrument and therefore are expensive. Another resorcinol measurement method is ultraviolet-visible spectrophotometry'. This method is convenient but its sensitivity is low. Some of proposed kinetic spectrophotometric method for determination of resorcinol were expensive or their sensitivity are low ${ }^{10,11}$. Therefore, the need for a sensitive, simple, rapid and sensitive kinetic spectrophotometric method for the determination of resorcinol is clearly recognized.

In this paper, we developed and validated a rapid, sensitive kinetic spectrophotometric method for the determination of resorcinol. Here, we report a kinetic method for trace 
determination of resorcinol, based on its inhibitory effect on the formaldehyde catalyzed oxidation reaction of of cresyl violet by bromate in acidic media.

\section{Experimental}

Doubly distilled water and analytical reagent grade chemicals were used during all of the experimental studies. Cresyl violet solution of $6.22 \times 10^{-4} \mathrm{M}$ was prepared by dissolving $0.020 \mathrm{~g}$ of the compound $(\mathrm{MW}=321.3$ ) in water and solution was diluted to the mark in a $100 \mathrm{~mL}$ volumetric flask.

Bromate stock solution of $0.015 \mathrm{M}$, was prepared by dissolving $0.626 \mathrm{~g}$ of potassium bromate $(\mathrm{M}=167)$ in water and diluting to $250 \mathrm{~mL}$ in a $250 \mathrm{~mL}$ volumetric flask. An aqueous formaldehyde stock solution, $1000 \mu \mathrm{g} \mathrm{mL}{ }^{-1}$, was prepared by diluting $2.5 \mathrm{~mL}$ of $37 \% \mathrm{w} / \mathrm{v}$ stock formaldehyde solution to $1 \mathrm{~L}$ with water.

Standard stock resorcinol solution $(1000 \mu \mathrm{g} / \mathrm{mL})$ was prepared by dissolving $0.1 \mathrm{~g}$ of resorcinol in water and diluted to $100 \mathrm{~mL}$ in a $100 \mathrm{~mL}$ volumetric flask. sulfuric acid solution was prepared by appropriate dilution of concentrated sulfuric acid (Merck).

Stock solution $(1000 \mu \mathrm{g} / \mathrm{mL})$ of interfering ions were prepared by dissolving suitable salts in water, hydrochloric acid, or sodium hydroxide solution. All glassware were cleaned with detergent solution, rinsed with tap water, soaked in dilute $\mathrm{HNO}_{3}$ solution $(2 \% \mathrm{~V} / \mathrm{V})$, rinsed with water and dried.

\section{Appartus}

Absorption spectra were recorded with a CECIL model 7500 spectrophotometer with a $1.0 \mathrm{~cm}$ quartz cell. A model 2501 CECIL Spectrophotometer with $1.0 \mathrm{~cm}$ glass cuvettes was used to measure the absorbance at a fixed wavelength of at $518 \mathrm{~nm}$. A thermostat water bath (Gallen Kamp Griffin, BGL 240 V) was used to keep the reaction temperature at $27{ }^{\circ} \mathrm{C}$. A stopwatch was used for recording the reaction times.

\section{Recommended procedure}

All the Solutions and distilled water were kept in a thermostated water batch at $27{ }^{\circ} \mathrm{C}$ for $20 \mathrm{~min}$ for equilibration before starting the experiment. An aliquot of the solution containing $0.20-8.0 \mu \mathrm{g} / \mathrm{mL}$ resorcinol was transferred into a $10 \mathrm{~mL}$ volumetric flask and then $2 \mathrm{~mL}$ $6.22 \times 10^{-4} \mathrm{M}$ cresyl violet, $0.6 \mathrm{~mL} 5 \mathrm{M} \mathrm{H}_{2} \mathrm{SO}_{4}$ and $0.2 \mathrm{~mL} 1000 \mu \mathrm{g} / \mathrm{mL}$ formaldehyde were added to the flask. The solution was diluted to ca. $8 \mathrm{~mL}$ with water. Then, $1.6 \mathrm{~mL} 0.015 \mathrm{M}$ bromate was added and the solution was diluted to the mark with water. The solution was mixed and a portion of the solution was transferred to the spectrophotometer cell. The reaction was followed by measuring the decrease in absorbance of the solution against water at $596 \mathrm{~nm}$ for $0.52 .5 \mathrm{~min}$ from initiation of the reaction. This signal (sample signal) was labeled as $\Delta \mathrm{A}_{\mathrm{s}}$. The same procedure was repeated without addition of resorcinol solution, and the signal(blank signal) was labeled as $\Delta \mathrm{A}_{\mathrm{b}}$. Time was measured just after the addition of last drop of bromate solution. Analytical signal was deference between blank signal and sample signal $\left(\Delta \mathrm{A}_{\mathrm{b}}-\Delta \mathrm{A}_{\mathrm{s}}\right)$.

\section{Results and Discussion}

Cresyl violet is a dye that can be oxidized with strong oxidizing agents at slow reaction. Formaldehyde can increasing rate of this reaction at ultra-trace level. We found that trace amount of resorcinol have a inhibitory effect on the this reaction. There are many methods, such as fixed time, initial rate, rate constant and variable time methods for measuring the kinetic species. Among these, the fixed time method is the most conventional and simplest, involving the measurement of $\Delta \mathrm{A}$ at $596 \mathrm{~nm}$ (Figure 1). Therefore, by measuring the decrease in absorbance 
of cresyl violet for a fixed time of $0.5-2.5 \mathrm{~min}$ initiation of the reaction, the resorcinol contents in the sample can be measured. Cresyl violet has the following structure( Figure 2).

DataStream - Scan

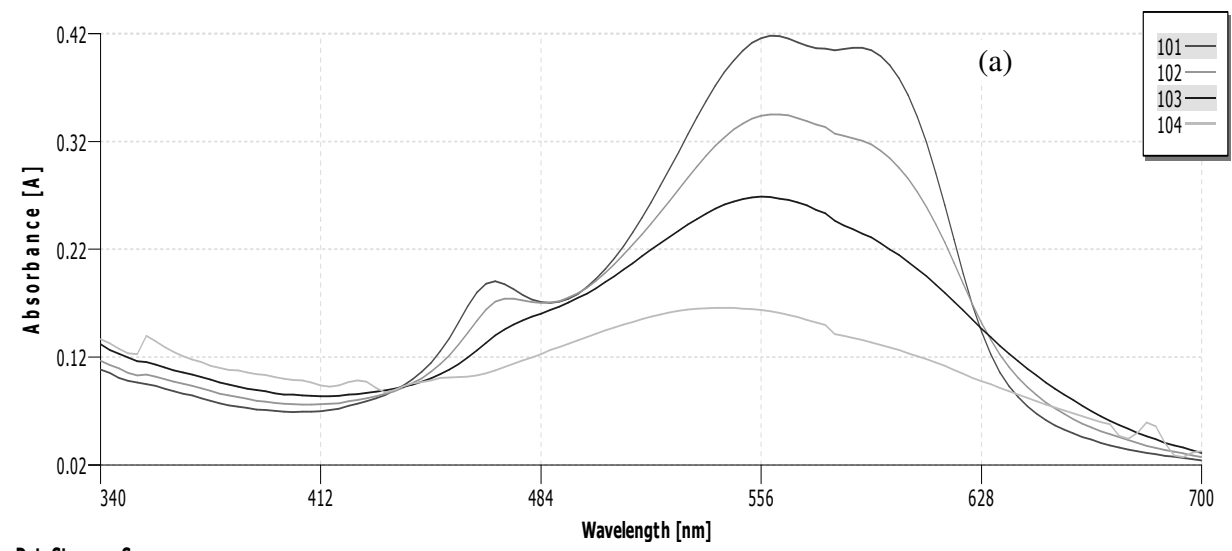

DataStream - Scan

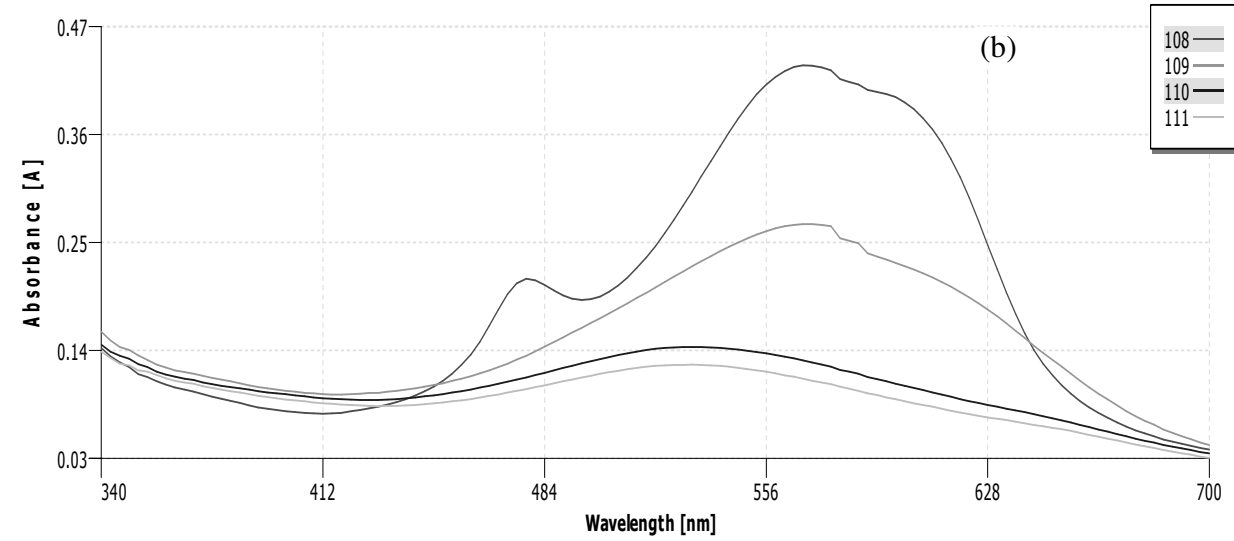

Figure 1. Absorption spectrum for the Resorcinol - Cresyl Violet $-\mathrm{BrO}_{3}{ }^{-}$system with time. (a) in presence of $0.4 \mu \mathrm{g} / \mathrm{mL}$ of Resorcinol (b) in absence of Resorcinol Conditions: $\mathrm{H}_{2} \mathrm{SO}_{4}, 0.3 \mathrm{M}$; Cresyl Violet, $1.24 \times 10^{-4} \mathrm{M}$; $\mathrm{BrO}_{3}^{-} 2.4 \times 10^{-3} \mathrm{M}$; formaldehyde $20 \mu \mathrm{g} / \mathrm{mL}$, temperature, $27^{\circ} \mathrm{C}$; interval time for each scan, $0.5,1.5,2.5,3.5$, and 4.5 from initiation of the reaction.

\section{Influence of variables}<smiles></smiles>

Figure 2. Structure of Cresyl Violet

In order to take full advantage of the procedure, the reagent concentrations must be optimized. The effect of acid concentration, cresyl violet, formaldehyde and bromate concentration and temperature on analytical signal was studied. 
The effect of sulfuric acid concentration on the analytical signal was studied in the range of $0.2-0.4 \mathrm{M}$. (Figure 3). The results show that the analytical signal increases with increasing sulfuric acid concentration up to $0.3 \mathrm{M}$ and decreases at higher con-centrations. Therefore, a sulfuric acid concentration of $0.3 \mathrm{M}$ was selected for further study.

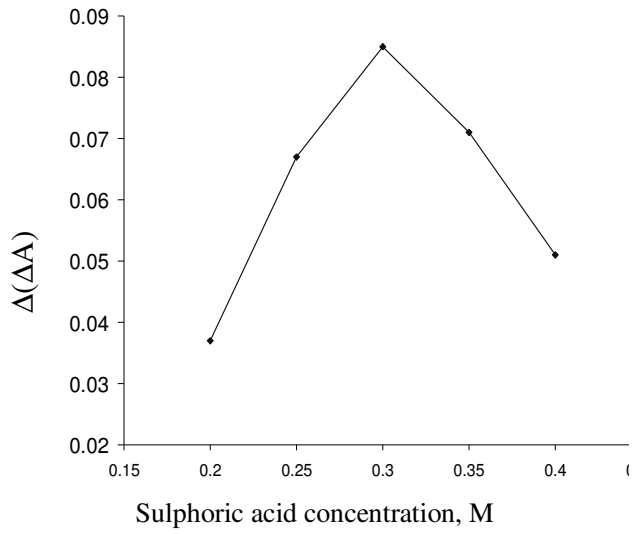

Figure 3. Effect of $\mathrm{H}_{2} \mathrm{SO}_{4}$ concentration on the analytical signal.

Conditions: Cresyl violet, $1.24 \times 10^{-4} \mathrm{M} ; \mathrm{BrO}_{3}{ }^{-}$ $2.4 \times 10^{-3} \mathrm{M}$; Formaldehyde $40 \mu \mathrm{g} / \mathrm{mL}$,

Temperature, $27^{\circ} \mathrm{C}$ and Time of 2 min from initiation of the reaction.

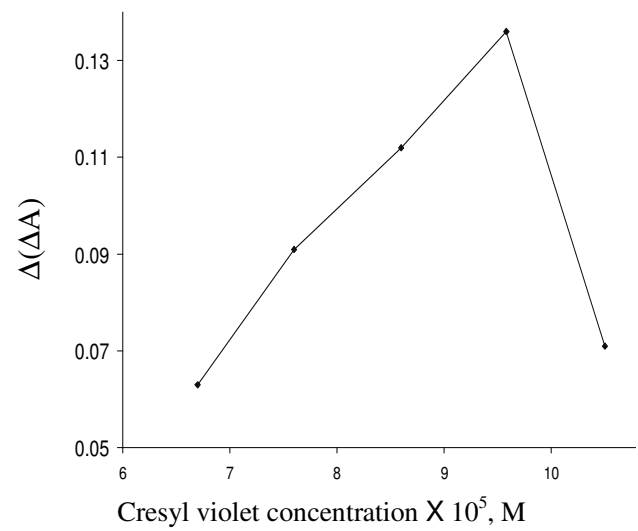

Figure 4. Effect of cresyl violet concentration on the analytical signal. Conditions: $\mathrm{H}_{2} \mathrm{SO}_{4}, 0.3 \mathrm{M} ; \mathrm{BrO}_{3}^{-}, 2.4 \times 10^{-3} \mathrm{M}$, Formaldehyde $40 \mu \mathrm{g} / \mathrm{mL}$, Temperature, $27^{\circ} \mathrm{C}$ and Time of $2.0 \mathrm{~min}$ from initiation of the reaction.

The influence of cresyl violet concentration on the analytical signal was studied in the concentration range of $8.7 \times 10^{-5}-1.36 \times 10^{-4} \mathrm{M}$ (Figure 4). The results show that analytical signal increases with increasing cresyl violet concentration up to $1.24 \times 10^{-4} \mathrm{M}$ and decreases at higher concentrations. Therefore, a cresyl violet concentration of $1.24 \times 10^{-4} \mathrm{M}$ was selected for further study.

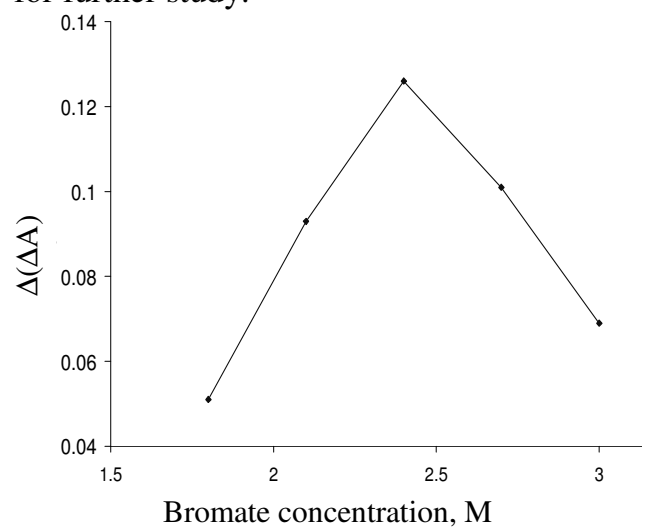

Figure 5. Influence of $\mathrm{BrO}_{3}^{-}$concentration on the analytical signal.

Conditions: $\mathrm{H}_{2} \mathrm{SO}_{4}, 0.3 \mathrm{M}$; Cresyl Violet

$1.24 \times 10^{-4} \mathrm{M}$ formaldehyde $40 \mu \mathrm{g} / \mathrm{mL}$;

Temperature, $27^{\circ} \mathrm{C}$ and time of $2 \mathrm{~min}$ from initiation of the reaction

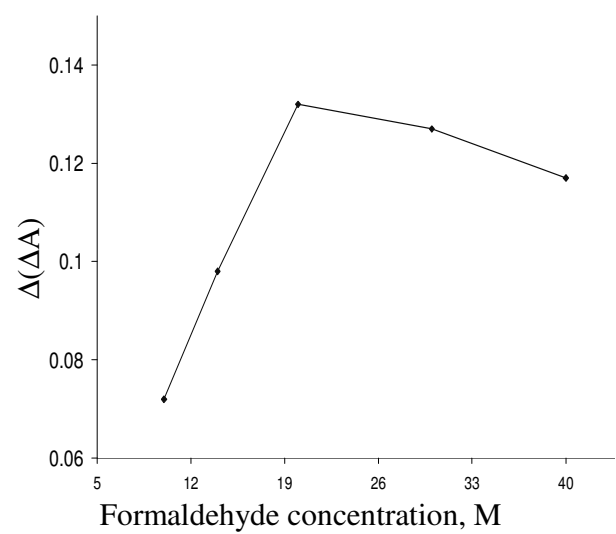

Figure 6. Influence of formaldehyde on the analytical signal.

Conditions: $\mathrm{H}_{2} \mathrm{SO}_{4}, 0.3 \mathrm{M}$; Cresyl violet $1.24 \times 10^{-4} \mathrm{M} ; \mathrm{BrO}_{3}^{-} 2.4 \times 10^{-4} \mathrm{M}$; Temperature, $27^{\circ} \mathrm{C}$ and time of 2 min from initiation of the reaction. 
Figure 5 shows the effect of the bromate concentration on the analytical signal for the range of $1.8 \times 10^{-3}-3 \times 10^{-3} \mathrm{M}$. This analytical signal increases with increasing bromate concentration up to $1.5 \times 10^{-3} \mathrm{M}$ and decreases at higher concentrations. Therefore, a final concentration of $2.4 \times 10^{-3} \mathrm{M}$ M of bromate was selected as the optimum concentration.

Figure 6 shows the effect of the formaldehyde concentration on the analytical signal for the range of $10-40 \mu \mathrm{gL}^{-1}$. Analytical signal increases with increasing formaldehyde concentration up to $20 \mu \mathrm{g} \mathrm{mL}^{-1}$ and decreases at higher concentrations. Therefore, a final concentration of 20 $\mu \mathrm{g} \mathrm{mL} \mathrm{L}^{-1}$ of formaldehyde was selected as the optimum concentration.

The effect of the temperature on the analytical signal was studied in the range $20-40{ }^{\circ} \mathrm{C}$ with the optimum of the reagents concentrations. The results showed that, as the temerature increases up to $27{ }^{\circ} \mathrm{C}$, the analytical signal increases, whereas higher temperature values decrease the analytical signal $\left(\Delta \mathrm{A}=\Delta \mathrm{A}_{\mathrm{b}}-\Delta \mathrm{A}_{\mathrm{s}}\right)$. Therefore, $27^{\circ} \mathrm{C}$ was selected for further study.

\section{Calibreation graph, precision and limit of detection}

Calibration graph were obtained using the fixed time method. This method was applied to the change in absorbance over an interval of 0.5-2.5 min from intiation of the reaction because it provided the best regresion and sensitivity. Under the optimum conditions described above, a linear calibration range $0.020-0.80 \mu \mathrm{g} / \mathrm{mL}$ of resorcinol. The equation of the calibration graph is $\Delta \mathrm{A}=9 \times 10^{-5} \mathrm{C}+0.0474(\mathrm{n}=7, \mathrm{r}=0.9994)$. The calibration graph was constructed by plotted of $\Delta \mathrm{A}=\Delta \mathrm{A}_{\mathrm{b}}-\Delta \mathrm{A}_{\mathrm{s}}$ at a fixed time method versus resorcinol concentration. The experimental $3 \delta$ limit of detection was $0.017 \mu \mathrm{g} / \mathrm{mL}$. The relative standard deviation for six replicate determination of 0.1 and $0.5 \mu \mathrm{g} / \mathrm{mL}$ resorcinol was 2.6 and $2.9 \%$ respectively.

\section{Interference study}

In order to assess the application of the proposed method to synthetic samples, the effect of various ions on the determination of $0.1 \mu \mathrm{g} / \mathrm{mL}$ resorcinol was studied. The tolerance limit was defined as the concentration of a added ions causing a relative error less than 3\% the results are summarized in Table 1 . The results show that method is relatively selective for resorcinol determination.

Table 1. Effect of foreign ions on the determination of $0.1 \mu \mathrm{g} / \mathrm{mL}$ resorcinol.

\begin{tabular}{cc}
\hline Species & Tolerance Limit $\left(\mathrm{w}_{\text {ion }} / \mathrm{w}_{\text {Resorcinol }}\right)$ \\
\hline $\mathrm{Mn}^{+2}, \mathrm{Hg}^{+2}, \mathrm{Te}(\mathrm{IV}), \mathrm{Se}(\mathrm{IV})$, & 1000 \\
$\mathrm{C}_{2} \mathrm{O}_{4}{ }^{-2}, \mathrm{HSO}_{4}{ }^{-}, \mathrm{CO}_{3}{ }^{2-}, \mathrm{HCO}_{3}{ }^{-}$, Tatarate, Borate, & 800 \\
$\mathrm{Co}(\mathrm{II}), \mathrm{Pb}(\mathrm{II})$ & 500 \\
Ethanol, methanol, ethanolamine, $\mathrm{SO}_{3}{ }^{2-}$ & 50 \\
$\mathrm{SCN}^{-}$ & 30 \\
$\mathrm{Br}^{-}$ & 5 \\
$\mathrm{I}^{-}, \mathrm{Cl}^{-}$ & \\
\hline
\end{tabular}

Table 2. Determination of resorcinol in synthetic samples.

\begin{tabular}{ccccc}
\hline Sample & $\begin{array}{c}\text { Resorcinol } \\
\text { Added, ng/mL }\end{array}$ & $\begin{array}{c}\text { Resorcinol } \\
\text { Found, } \mathrm{ng} / \mathrm{mL}\end{array}$ & $\begin{array}{c}\text { Recovery } \\
\%\end{array}$ & $\begin{array}{c}\text { RSD, } \\
\mathrm{n}=5\end{array}$ \\
\hline Well water & - & - & - & - \\
Well water & 100 & 94 & 94 & 2.6 \\
Well water & 500 & 528 & 105.6 & 2.8 \\
\hline
\end{tabular}

Sample analysis

In order to evaluate the applicability of the proposed method, water samples were analyzed to determine resorcinol contents. The results are presented in Table 2. Good recoveries with precise results show good reproducibility and accuracy of the method. 


\section{Conclusion}

The kinetic spectrophotometric method developed for the determination of resorcinol is inexpensive, uses readily available reagents, allows rapid determination at low operating costs, and shows simplicity, low limit of detection and good precision and accuracy compared to other kinetic procedures.

\section{Aeknowledgments}

The author are Thankful to the Islamic Azad University-Majlesi Branch for the support of this work.

\section{References}

1. Sangli A B and Kanabur V V, Environ Ecol., 1998, 16(3), 642-644.

2. McMahon G P and Kelly M T, Anal Chem., 1998, 70, 409-414.

3. Fiehn M Jekel, J Chromatogr A, 1997, 769, 189.

4. Kim H, Roh H, Lee H J, Chung S Y, Choi S O, Lee K R and Han S B, J Chromatogr $B, 2003,792,307-312$.

5. Mikami E, Goto T. Ohno T, Matsumoto H and Nishida M, J Pharm Biomed Anal., 2002, 28, 261.

6. Hua C, Jian Z, Feng X, Chun-Ze L and Guo-Hui W, Anal Chim Acta., 2004, 511, 273.

7. Engeberth J, Schmelz, E A, Alborn H T, Cardoza Y J. Huang J and Tumlinson J H, Anal Biochem., 2003, 312, 242.

8. Lartigue-Mattei C, Lauro-Marty C, Bastide M, Berger J A, Chabard J L, Goutay E and Aiache J M, J Chromatogr B, 1993, 617, 140.

9. Glombitza B W and Schmidt P C, J Pharm Sci., 1994, 83, 751.

10. Parham H, Pourreza N and Cheraghi S, Anal Lett., 1999, 32, 1917.

11. Jing F, Tao Z, Jianhui S and Maohong F, J Fluoresc., 2007, 17, 113. 


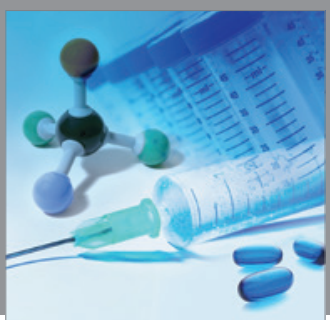

International Journal of

Medicinal Chemistry

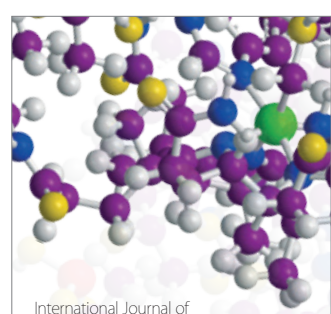

Carbohydrate Chemistry

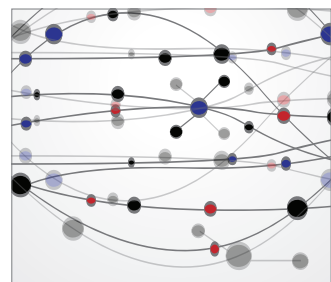

The Scientific World Journal
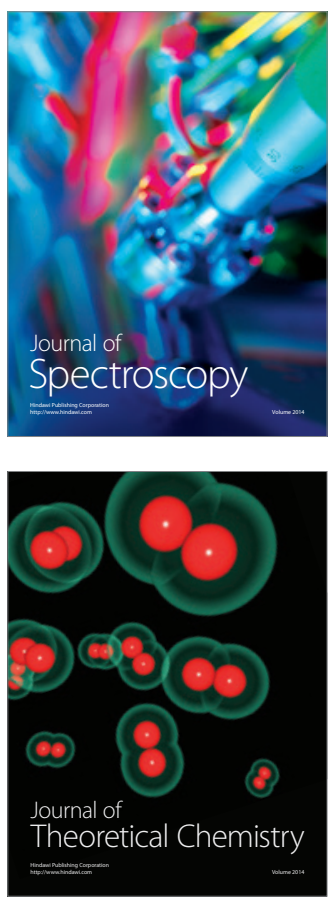
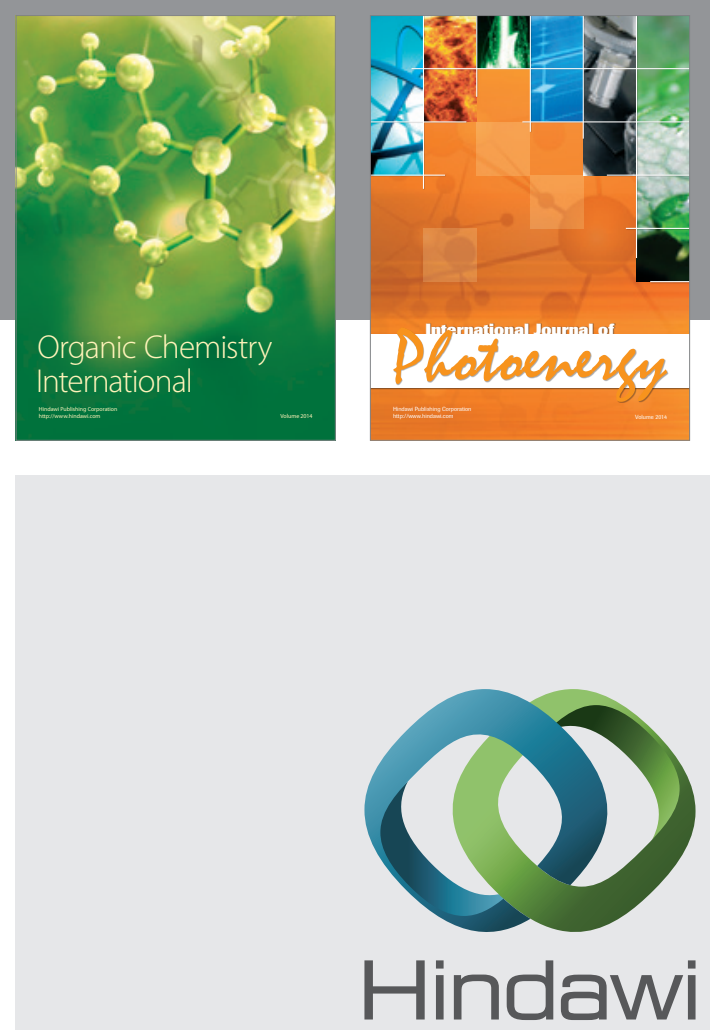

Submit your manuscripts at

http://www.hindawi.com
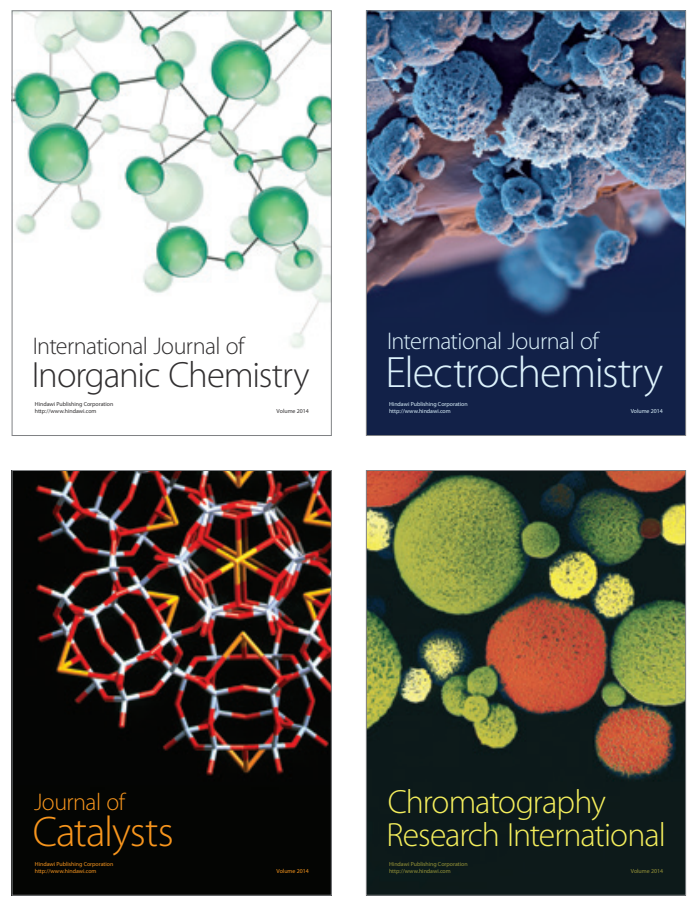
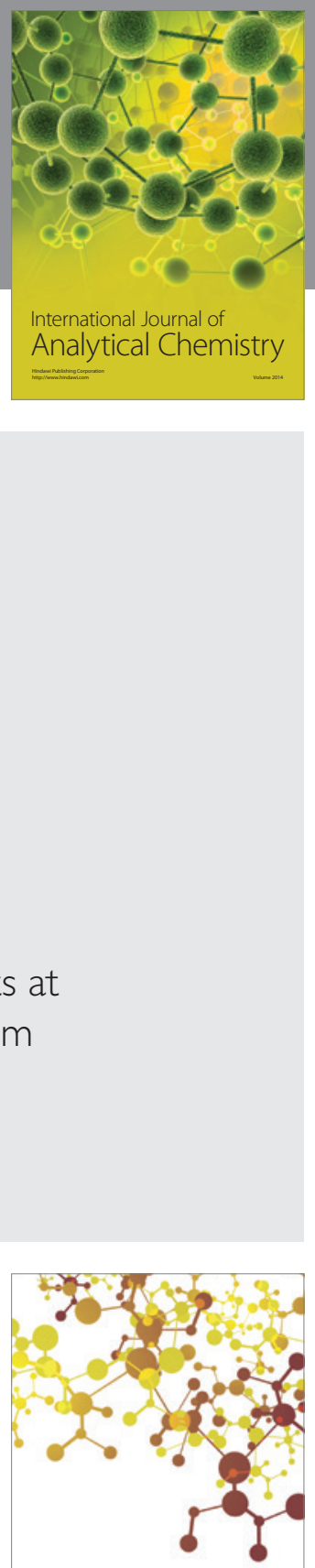

Journal of

Applied Chemistry
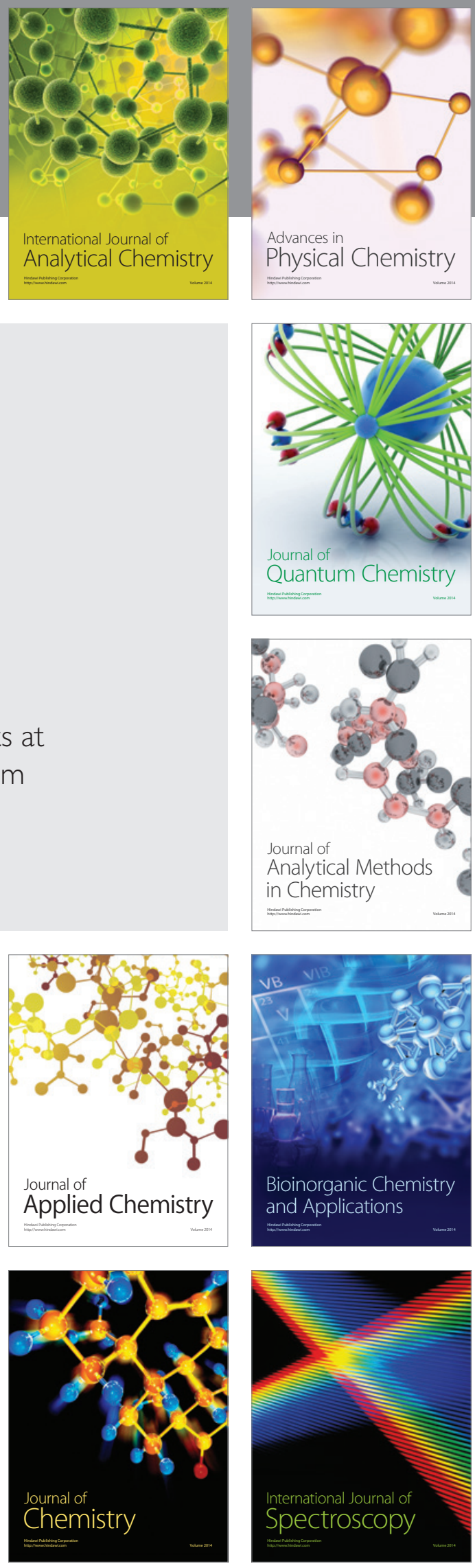